\author{
$L \Lambda-U R--82-2981$ \\ DE83 002083
}

TITIE. A PORTABLE NEUTRON SPECTROMETER/DOSIME TIR

\section{MASTER}

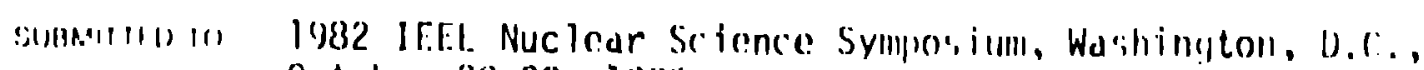
0c.toher 20)-2.2, 1982.

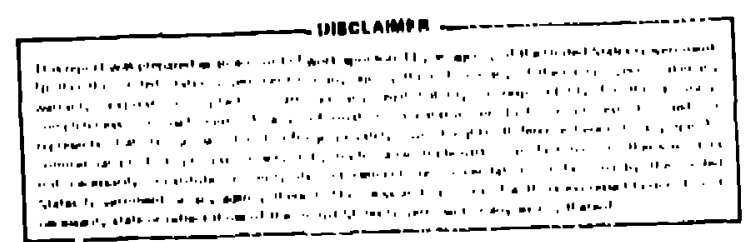

MOTICE

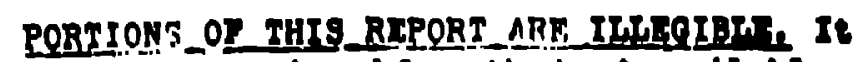
has beon roproduoed frou the beat avallablo cops to porndt the broed ant poselblo avaliasises?

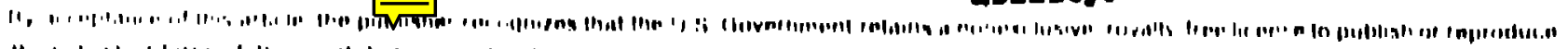

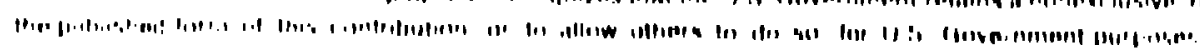

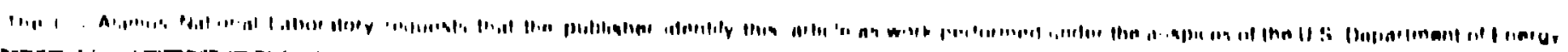

Los Allamos Los Alamns National Laboratory 


\title{
A PORTABLE NEUTRON SPECTROMETER/DOSIMETER
}

D. A. Waechter, B. H. Erkkila and D. G. Vasilik

\author{
Healtin Division \\ Los Alamos National Laboratory \\ Los Alamos, New Mexico 87545
}

\section{SUMMARY}

As part of the continuing DOE effort to upgrade personnel neutron dosimetry, ' the Health Division at Los Alamos has developed a portable, battery-operated, computerized neutron spectrometer/dosimeter. ${ }^{2}$ The instrument has a built-in tissue-equivalent LET neutron detector, 128-channel pulse height analyzer with integral liquid crystal display, ${ }^{3,4}$ and a microcomputer system which calculates dose and dose rate from neutrons : ncident on the detector. The instrument will, at the user's option, display a raw data spectrum or a spectrum of rad or rem as a function of keV per micron of equivalent tissue. The dosimeter will also calculate and display accumulated dose in millirad and millirem, as well as giving the user noutron dose rates in millirad and millirem per hour.

\section{(IENERAL. DESCRIPTION}

The neutron spectrometer/dosimeter was developed to provide the hedlth protection technician with full capability for field messurement.s of high energy neutron flux. The instrument, shown in 1ia. 1, is packaned in a

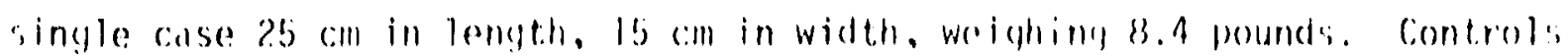
consist of a power switch and a 16-key kryboard which calls all of the spectroneter and dosimetor functions of the instrument. The spectrometer/

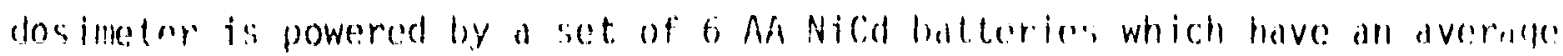
lifetime of 4 to $b$ hours.

The neutron spectrometer/dosimeter is designed around a linear onervy transfor (1.LT) proportional counter. Ihis counter consistes of a hollow

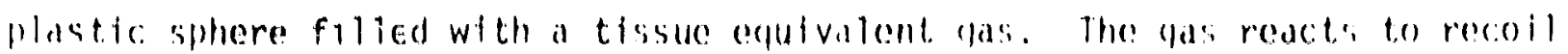
protons generated in the plastic: wall in much the salle way ats a 7 -miccon shore of human tissue. Incoming neutrons yenerate rocoil protons in the lissue equivalent wall. The charye deposited by these protons is directly

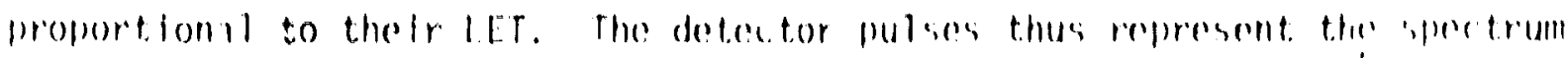

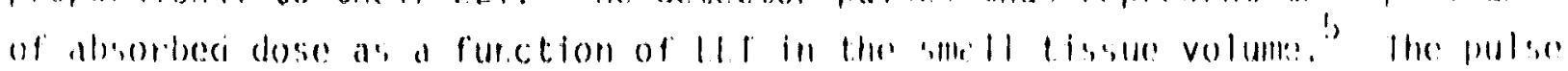


output from the counter is digitized and converted to spectral information. From the resulting pulse height spectrum accumulated dose is calculated and displayed. The dose rate is determined by dividing accumulated dose by the time elapsed, up to 20 hours. The resulting dose rates are displayed airectly below the figures for accumulated dose.

A useful feature built into the LET counter is a calibration syctem. This system consists of an internal Cm244 alpha scurce which can be exposed to the detector by activating a built-in magnetic shutter. A spectrum of the alpha source is taken and the gain of the input amplifier is adjusted to place the alpha peak in a predeterimined ch?nnel number in the 128-channel analyzer. When the alpha peak is in the right position, all the constants used to calculate dose from the pulse height spectrum will be valid.

\section{ELECTRONIC DESCRIPTION}

A bluck diagram of the neutron spectrometer/dosimeter is shown in rig. 2. It consists of three basic sections: input signal processing unit, microcomputer, and display.

The input section is a standard pulse height analyzer front end. Pulses from the detector are shaped and amplified by a preamp and then are fed, with the proper timing, to an 8-bit analog-to-digital converter. The converter outputs a digital word whose inagritude is proportional to the height of the irput pulse.

The microcomputer is designed around an NSC800 low power CMOS microprocessor manufactured by National semiconductor. The microprocessor is supported by $8 \mathrm{~K}$ bytes of program memory and $3 \mathrm{~K}$ bytes of data memory, all of which are low power CMOS in order to keep battery drain to a minimum. The memory has been made sufficiently large to allow for fiuture expansion of functions. The user communicates with the computer through a 16-key keyboard located or the front panel of the instrument. With the keybuard all of the functiome and display modes can be readily called up.

The diphay is a dot matrix led array 80 dots, wide and 28 dots high. The microcomputer communicates wtih it throuch two legic: cards, one of which $i$ i provided by the display manufacturer as bart of the display. The display loyic contains all the circuits necessary to convert the data from the microcomputer to readable spectral or dost: information, as refuired. Also part of the display logic is an on-board memory array which stores current diplay infurmation. This array with its associated logic refreshes the display periodtcally so that the control processor doesn't have to be tied up for long periocis rewriting the same data to the display over and over. 


\section{FUNCTIONAL OESCRIPTION}

All of the functions of the spectrometer/dosimeter are accessible via the keyboard located on the front panel of the instrument. This keyboard includes keys to gererate and move pulse spectra, generate dose information,

1 initiate signal acquisition.

Signal acquisition is controlled by two keys, ACQ and HLT. The acquire key, $\triangle C Q$, causes tile input circuits to be enabled and initiates input signal proces ing by the microprocessor. Signal processing continues until the halt key, HLT, is pressed. The HLT key inhibits the passage of further input pulses through the system.

There are five keys which allow the operator to generate various types of displays. Of these five, all but the DOSE key cause different types of spectra to be generated. The DOSE key, when pressed, will cause the microprocessor to calculate from the raw data accumulated dose and dose rate. The information is then presented on the display in units of millirad, millirem,

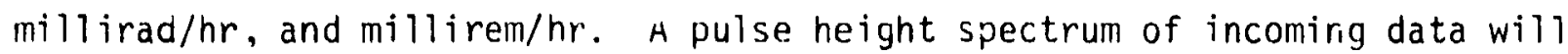
be generated on the display when the DATA key is pressed. Pressing the LOG key yields a spectrum of the same data displayed in semilog format. When the RAD key is pressed the instrument will present a plot of the dose in millirads as a function of keV per micron of tissue. The REM key performs a similar function but displays accumulated dose in millirem as a function of keV per micron of tissue.

Four modify keys are previded on the instrument to modify displaved spectra, aiding in the analysis of spectral information. The up arrow and down arrow keys are vertical scale control keys. When pressed, they scale the specirum up or down. The left arrow key allows the user to rol! the display left horizontally, ten channels at a time, so that a 11128 channeis of any' spectra may be viewed. In the same way, the right arrow key rolls the display to the right ten channels at a time.

Finally, there are two control keys on the kevboard. The first of these is the Cl.R or clear key. The CLR key simply clears whatever is being displayed, be it dose or spectral information. This key serves as an aid in calibratina the yain of input sircuits and finds use whenever the ol arator needs to clear the data memories. The other control key is reset, RST. The RST key reinitializes the instriment. It has the some effect as turning the power off and back on. The RST key is used to start the dosimeter while heoping all the internal power supplies stable. 
The neutron spectrometer/dosimeter was designed to aid those concerned with neutron dosimetry in characterizing hiciler energy neutron fields. It is important to note that the instrument is not designed for neutrons with energies below about $100 \mathrm{keV}$. The $s m^{-11}$ size of the dosimeter and its simplicity of operation ensure that it should find wide use in any area where workers might be exposed to fields of high energy neutrors.

\section{ACKNOWLEDGEMENTS}

The authors wish to thank $K$. Dolberg of the Health Division for xcellent illustration services. Our thanks also to $F$. Trujillc for mechanical support throughout the course of the project. This work was performed under the auspices of the U.S. Department of Energy.

\section{REFERENCES}

1. Leo G. Faust, Proceedings of the Eiyhth DOE Workshop on Personne 1 Neutron Dosimetry, PNL-SA-9950 (1981), p. 5.

2. W. Quam, T. Del Duca, W. Plake, G. Graves, and T. DeVore, IEEE Trans. Nucl. Sci., NS-29, No. 1 (1982), p. 637.

3. M. A. Wolf and C. U. Umbarger, IEEE Trans. Nucl. Sci., NS-27, No, I (1980), p. 322.

4. D. A. Waechter, M. A. Wolf and C. J. Umbarger, IEEE Trans. Nucl. Sci., NS-z8, No. 1 (1981), p. j01.

5. H. H. Rossi and Walter Rosenzweig, Radiation Research 2 (1955), p. 417. 


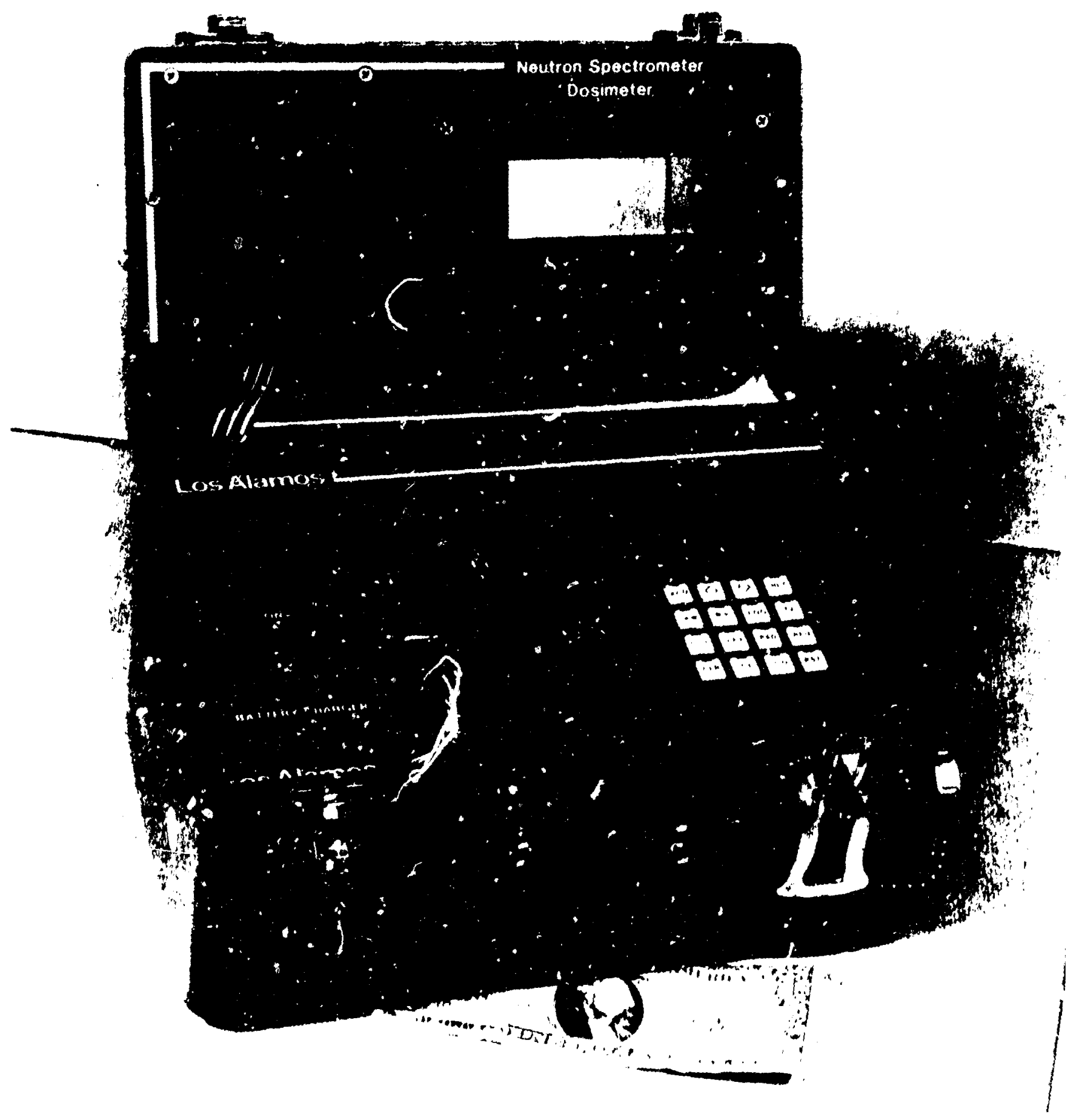




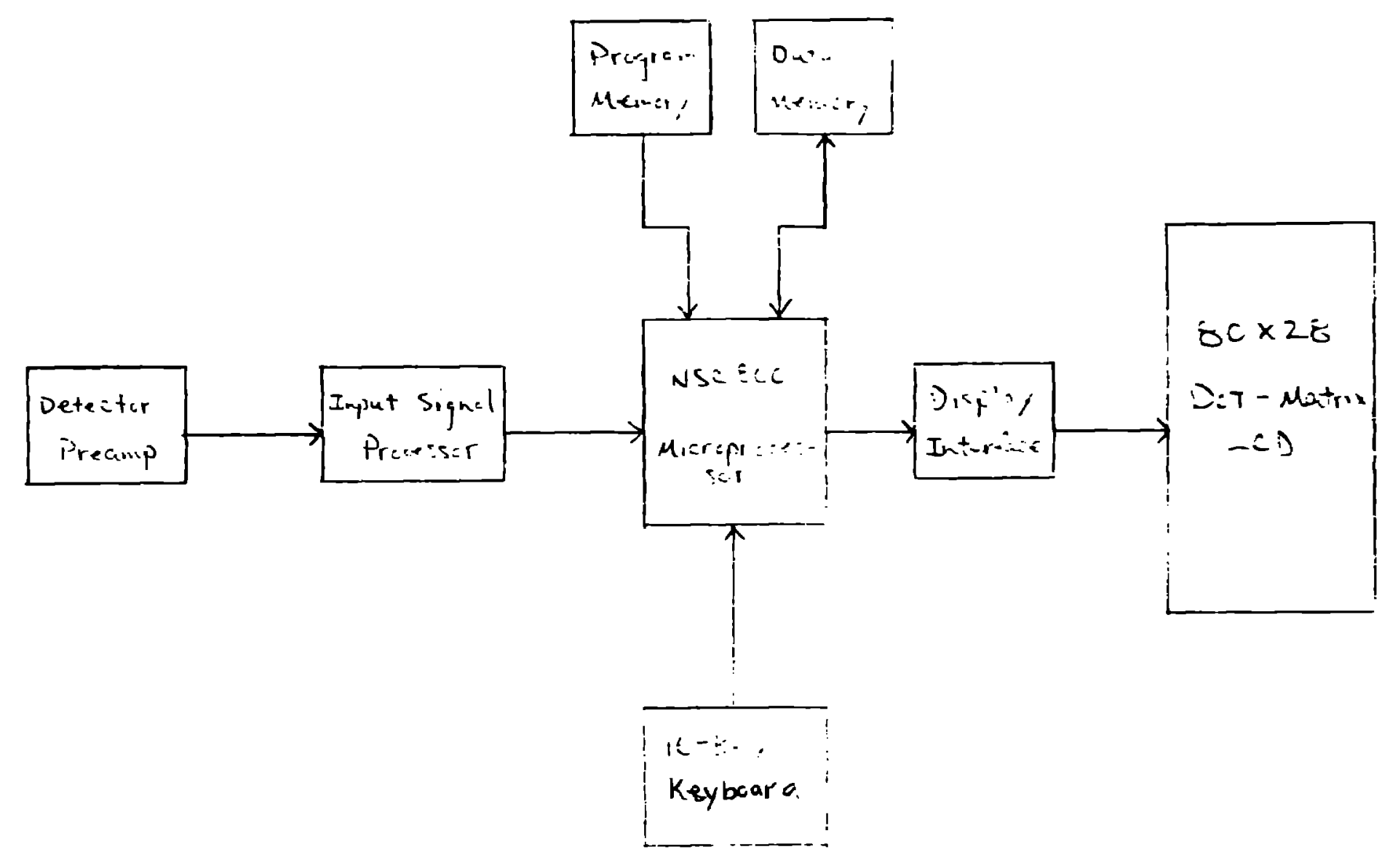

F..:

SYSTEM RLCCK DIAGRAM 
D. A. Waechter, B. H. Erkkila and D. G. Vasilik

\author{
Health Division \\ Los Alamos National Laboratory \\ Los Alamos, New Mexico 87545
}

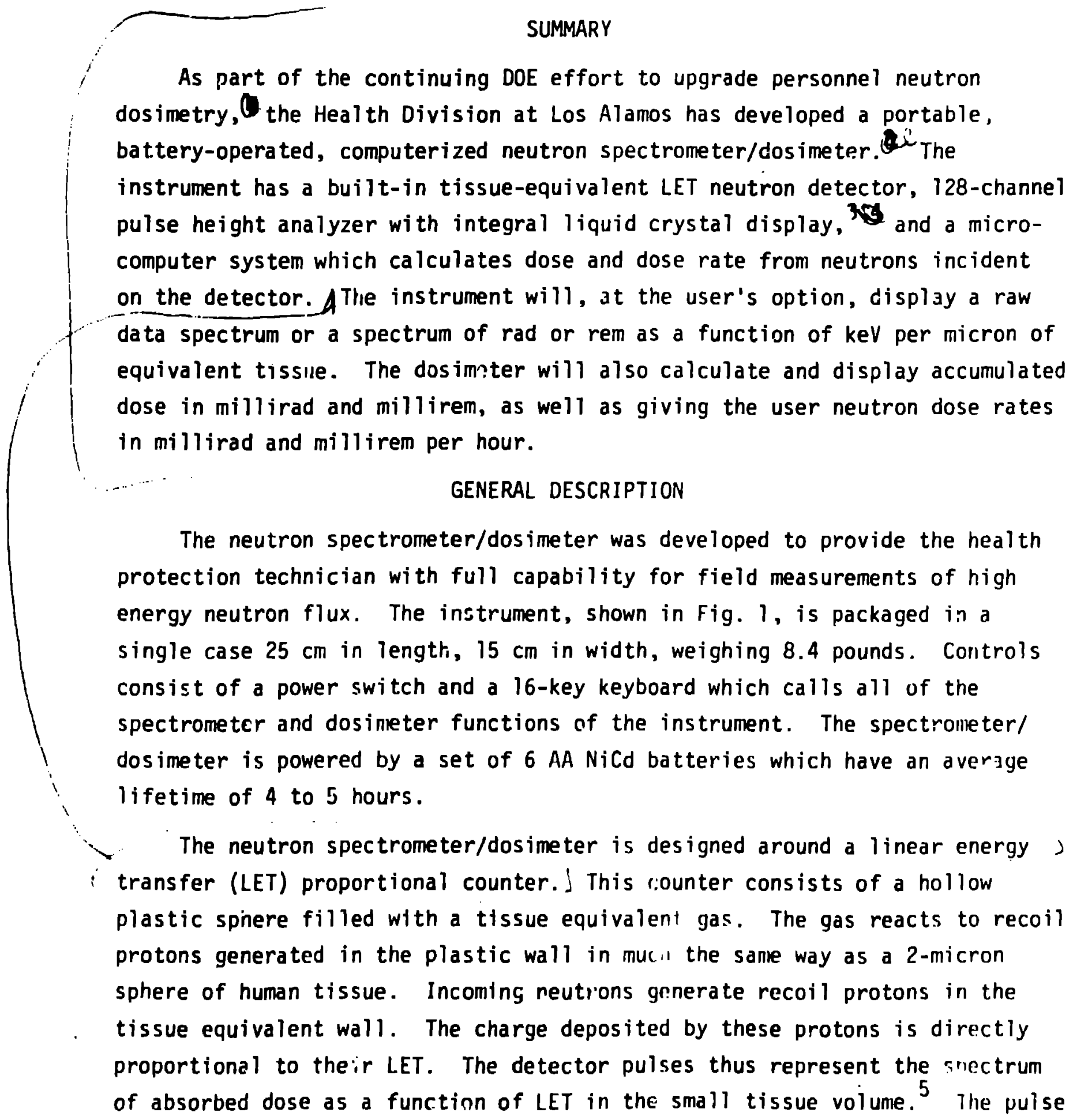

